\title{
Amateur Astronomy*
}

\author{
Valuable Contributions Made by Volunteer Workers in the Field
}

\author{
By W. E. Plummer, M.A., F.R.A.S.
}

IN considering the question of amateur astronomy, I suppose the first question to decide is, Who is an amateur? It is a question which in some direction has, I believe, given anxiety to many, as the borderland separating the amateur from the professional can be a very narrow one. The general idea or definition is that an amateur is a man who takes up science as a hobby, who has other occupations, but finds his relaxation or amusement in some scientific investigation, for which he has had no special outside training. He is usually self-taught in the branch of knowledge which he finally selects for study, and inasmuch as a self-taught man is generally at a disadavantage as compared with those who have enjoyed professional instruction and guidance, the term has, in some instances, come to be regarded as a reproach, an utterly false impression, which I shall do my best to correct. There is, I know, in various walks of life a certain amount of jealousy between the professional and the amateur, a tendency to despise the work of the one as fragmentary and disconnected, as unmethodical and superficial, to which the amateur retorts by complaining that the professional is mechanical, unimaginative, and steeped in routine. I would fain hope that that spirit of ungenerous recognition or mutual dissatisfaction does not exist to any great extent in astronomy. I give you the following reason for the grounds of my belief. If you look down the list of those to whom the medal of the Royal Astronomical Society has been awarded in past years, you will find a considerable number of so-called amateurs. This tells us, or, at least, I think so, that the work of the amateur is not less valuable than that of the professional, and that it is as readily welcomed and recognized. This should be an encouragement to all amateurs to go and do likewise. In the vast field of amateurs to go and do likewise. In the vast field of
research there is room for all, and just as amateurs have research there is room for all, and just as amateurs have
rendered yeomen's service in the past, so I firmly believe that they will be needed, and will enrich astronomy in the future. And standing here with the wish to inspire all to use their best endeavor, permit me to recall to you in the briefest possible manner the names and the work of some of those who have received this greatest measure of recognition that it is possible for the Society to bestow. In this place, surely the name of Dr. I. Roberts occurs to you, who, though his work in some particulars has been superseded by later workers with improved equipment, revealed to the world that delicacy and complexity of structure in the nebulæ at which we have all marveled, and on which we have all speculated. He enabled the student of the universe to gaze on and scrutinize these student of the universe to gaze on and scrutinize these
ever-beautiful and mysterious objects at his leisure, ever-beautiful and mysterious objects at his leisure,
instead of utilizing those few moments on the finest of instead of utilizing those few moments on the finest of
nights and uncomfortable surroundings. This, I take it, nights and uncomfortable surroundings. This, I take it,
was his reward, the consciousness that he had given to the world new thoughts and new facts, that inquiry and analysis were easier because he had worked and struggled. Another name equally familiar to you is that of Mr. W. F. Denning, whose perseverance and untiring industry have awakened fresh interest in the subject of meteors. have awakened fresh interest in the subject of meteors.
Mr. Denning had great difficulties to contend against, not the least of which was ill health. He was hampered, too, by the cares of an exacting business, and there were other reasons known to some of you which might have depressed his energies. But Mr. Denning ever exhibited that dogged determination which is characteristic of the amateur. Mr. Denning threw all his energies into his amateur. Mr. Denning threw all his energies into his
self-imposed task, and is a worthy example we should all be proud to imitate, whether in his single-hearted and enthusiastic devotion to the discovery of truth or in rising superior to frowning discouragement and bodily weakness.

Dr. Common is another whose example should prove stimulating and instructive. Long exposure in photography was in its infancy when he was at work in the 'eighties. His early attempts on the nebulæ of Orion were failures. The stars were seen as lines, and the nebulæ proper presented a small and faint stain upon the plate. But such failures were, to the man possessed of the true spirit of the amateur, suggestive of the necessity of improving the driving of the clock and the procuring of a more sensitive plate. He had not only the gratification of present success, but also the consciousgratification of present success, but also the conscious-
ness that all those following in his footsteps have entered into his labors. He had the conviction of having accomplished something for the advancement of science, of making its acquisition easier to others. Frank Maclean and Sir W. Huggins are names to hold in fond remembrance as workers in other departments of our science indicating what amateurs have affected in the past, and confincing us that such men, animated by the same motives, and propelled by the same eagerness. will be needed in the future.

Before leaving this part of my subject I would like to make another remark, which may or may nor be relevant. You will notice that all these names are English, and do not find among the list of medallists any foreigner who, under our rough-and-ready definition, could be classed as an amateur. I do not think that this is accidental; it rather points to some national characteristie, that there is something peculiarly English in amateur astronomy, something that appeals more to Englishmen than to other nations. It would be very interesting if we than to other nations. It would be very interesting if we
could discover the explanation of this peculiarity. It could discover the explanation of this peculiarity. It
can hardly be traced to our climate, for that is sufficiently depressing, nor in the amount of leisure at com mand, for we are as busy as most nations. Navigation, our pride in the sea, may act as an unconscious incentive; but more probably this taste is due to example. Accident probably led the way. Perhaps the fame and the royal favor that attached to the elder Herschel, himself an amateur, may have induced others to follow in his steps. But, looking to what amateurs have effected in all branches of science, in physies, chemistry, biology and other departments, I am inclined to see a national trait, a distinctive feature, which separates us from all other nations of the world. If this be true, then I say that it is a most precious inheritance, and one to be guarded jealously. The name of "amateur" is one to be cherished, and not to be despised. That is my message to you to-night-to make you esteem more highly th ardent voluntary worker, whose labors, in no insignificant way, have placed English science on the pedestal it occupies. Every nation, owing to a number of circumstances, possesses its own peculiarities which render it better fitted than its neighbors to forward some particular part of the work on which the progress of science depends. Let us encourage each other to take that share of work for which national character and educa tional training best adapt us. If it be not given to us to imitate the plodding, exact experiment of the German, if the domain of accurate measurement belongs to France, if the metier of the American is the production of gigantic apparatus, while our forte lies in voluntary exertion in all branches of science indifferently, it seems probable that the greatest good will be obtained by following the path of least resistance, not by attempting to transplant the methods and imitate the work of other nationalities -in a word, to struggle on, following the lines which have hitherto proved fructiferous. With us, in our
scheme of scientifie progress, the amateur is one great and scheme of scientifie progress, the amateur is one great

Now, the amateur, in the light in which we are considering him here, usually begins his study or research when the mind is sufficiently developed to form an entirely unbiased opinion. One consequence of this, it seems to me, is a great advantage - viz., that we have a section of scientific men beginning their work untrammelled by preconceived notions which a systematic training in science is bound to instill. Whatever is taught in an early age must necessarily be taught in a more or less dogmatic manner, and, in whatever way it is taught, experience shows that it is usually received in a dogmatic spirit. The matured man approaching the subject takes his own course, afraid of neither ridicule nor criticism. His very ignorance is his shield. He has his own view of what he intends to accomplish, and he probably does not know the particular direction or method in which the so-called trained mind would go to work to obtain the needed result. This is not necessarily a disadvantage; indeed, in particular cases it is an advantage. It does not follow that because the amateur pursues his own method he is wrong or inferior. Further, if he possessed a complete knowledge of everything bearing upon a particular subject, he might be discouraged, or consider himself not sufficiently informed. The stimulus of inquiry would be gone. In some cases such knowledge may be essential; in others it is a hindrance. Different types of men incline to different types of research, pursue difierent methods, and it is well to preserve all variations in the struggle. My point is that a problem or a research cannot a approached in too many ways. Freshness of view, novelty ö́p conception, are the peculiar features that amateurs bring, to the task, ignoring the stereotyped methods that thave been sanctioned by long usage. To lose or despise those factors which make for success would be a great mistake. They are qualities that need encouragement. I am indebted to Prof. Schuster, who describes an amateur as one who learns his science as he wants it and when he wants it, for the following simile: The engine which works out the great problems of Nature may be likened to a thermodynamic machine. The
amateur supplies the steam, and the hidebound professional furnishes the cold water. The former, boiling over with ill-considered and fanciful ideas, does not like the icy douche, and the professional scientist does not like the latent heat of the condensing steam; but, nevertheless, the hotter the steam and the colder the water, the better works the machine. Sometimes it happens that the boiler and the cooler are both contained in the same brain, and each country can boast of a few such in a century; but most of us have to remain satisfied with forming only an incomplete part of the engine of research. Among those who have combined the zeal of the enthusiast and the caution and restraint of the professional scientist, he would place such honored names as those of Faraday and Joule in the army of amateurs-men who would have been impossible in any other country, and that we have not been accustomed to consider them in this light.

It may be asked at this point whether there is any possibility of losing or diminishing the influence of amateurism as a lever to raise scientific activities. You cannot train a man to be an amateur, but you may deter one who would fill that rôle with satisfaction and success. It would carry me too far to-night to attempt to dissect the causes that may operate injuriously upon the exercise of the talents which peculiarly belong to the amateur. But it is possible one ill-effect may be found in insisting upon too great uniformity in education. To revert to our thermodynamic machine, no work can be got from it when there is no change of temperature. When all bodies are at the same temperature, there may be an unlimited amount of energy present, no part of which is available for transformation. We get no work from still water if it be all at the same level; so, in like manner, we can get no progress from minds that are molded on one pattern and work in one groove. I must not forget the astronomical amateur in considering the general proposition; but I would also like to mention the danger lurking in the tendency to too early specialization in particular directions. Curiosity can be cooled down too early. Forward summers mostly have an early spring, as Shakespeare taught. The brain can become jaded, maturity be too soon reached. The early-trained is apt to think that he has exhausted the sources of knowledge, and that all i vanity. If scientific theories were not taught till a man had reached an age when he was able to form an independent judgment, there would be a greater hope of retaining that originality of ideas, and that diversity in method of work, which I suggest has been a distinguishing feature in the scientific development of this country, and enabled our amateurs to hold a prominent position in the history of investigation.

But I am anxious to keep away from the general amateur, whose analysis is very interesting, to confine myself solely to the part that the amateur plays, or may play, in astronomy. I would, too, look rather on the hopeful and encouraging side than on the depressing and deterrent. I want to impress you with the share that amateur astronomy cin take, and is, perhaps, destined to take, in the future. I want especially to convince you that the day of the amateur is not past--that thyre is still work for him. The conditions of observing may change, the problems may be new, the research may be more recondite and more difficult than formerly; but the amateur is not to be elbowed out of the crowd that is pressing on to the goal; and perhaps the readiest way to win confidence would be to read some words which fell from the Director of the Mount ilson Observatory, than whom no man is more competent to speak, either on account of his education, his work, or his success. For let me remind you that there was a time when he was an amateur in the ordinary acceptance of the term, and, by the definition I am going to give you presently, you will see that, in the truest and best sense of the word, he remains an amateur still. Moreover, there is a particular fitness in quoting such an authority, for he of all men has revelled in the use of large telescopes. If any man knows the importance of apparatus to which the amateur cannot hope to have access, it is Prof. Hale; but, notwithstanding, or perhaps because of, such knowledge, no man is more eager to assure the owner of small means, the ardent amateur, that there is still work for him. These are his words "I have sometimes heard it said that the great cost of modern observatories tends to discourage workers with small instruments-observers who are no less interested in the pursuit of astronomical research than the astronomers in large institutions. It seems to me that if there is any serious discouragement, due to this cause, of men 
who are engaged in original research with small telescopes and inexpensive apparatus, it is a question whether large observatories should be established."

Here is a man whose reputation rests on what he has been able to accomplish with large telescopes, who has revealed to us more of the Constitution of the Sun than any living authority, who has used high resolving power and very high linear dispersion, who recognizes that in the future we must be prepared to use even more powerful instruments, and yet he is willing to forego the use of this powerful apparatus if it discourages, if it deprive the man of small means of pursuing science in his ow way. And he goes on to give us the reason for this self-
denying decision. For at any period in the progress of denying decision. For at any period in the progress of
observational astronomy there are two most important subjects for consideration. One relates to the accomplishment of a great amount of routine observation and the discussion of results, and the other relates to the introduction of new ideas, and to the beginnings of new methods which will make the astronomy of the future.
think we will all admit that the introduction of new ideas think we will all admit that the introduction of new ideas
is quite as important as the prosecution of routine reis quite as important as the prosecution of routine re-
search, and that if any cause whatsoever tends to discourage the men from whom the new ideas might be likely to proceed, that cause of discouragement should be set aside if possible. You see he does not think it impossible that some amateur, working on original lines, untrammelled by authority and precept, may strike out processes that will render the use of large telescopes unnecessary. In these days we have seen the combination of the photographic plate in connection with very moderate reflectors reveal more than the largest telescopes of thirty years ago would show at the eyepiece. What has not the new thought of the application of photography given us, and can anyone suppose that
that is the last of the great thoughts that will revolutionize astronomical science. We should remember, too, that this suggestion of the invigorating force of new ideas comes from a man who, working with small means, in vented the method by which photographs are now made of all the prominences visible round the entire circumference of the Sun, with a single exposure, and by which faculæ are clearly shown even in the brightest portions of the Sun's disk. We want someone now possessed of a new thought, gifted with scientific imagination. such as he who would tell us how to record the Coronal surroundings of the Sun at other times than at total eclipse. It is probably not the way it will be done at all. Not by old methods, not by increasing the efficiency of the power in our hands now, will that problem be solved. Only by our hands now, will that problem be solved. Only by
originality of thought, only by the exercise of powerful imagination will that problem and many others be sølved, as they will be solved, not perhaps in my time, but hope in the near future, by the energy now being ex-
pended in research by the younger generation of astronomers.

Slow indeed is progress when measured by what we want to know, and yet never was progress more rapid than during our time, thanks to the efforts of amateurs no less than to professionals. And therefore the director of the great solar observatory, that wonderful focus of activity, in which one hardly knows whether he ough most to admire the exhaustless energy or the admirable ingenuity which he finds displayed, who knows all this and much more, says emphatically: "Therefore, I say in all seriousness that it is a fair question whether large observatories with powerful instrumental equipment should be established if they tend to keep back the man who is pursuing the subject with less expensive appliances, and is introducing, through his careful considerawhich in the process of time will take the place of the old ones."

Believe me, never before had the astronomer so much work-good, hard, yet hopeful work-before him as
to-day. He who is leaving the stage feels that he has to-day. He who is leaving the stage feels that he has
only begun, and must leave his successors with more to do than his predecessors left him. For every new discovery suggests fresh lines of work and research. It is unsafe to neglect any source of information, unwise not to take advantage of what seems little likely to lead to fruitful results. Only a few years since, the number of smal planets that figured in our catalogues was so great that any new discovery was unwelcome, and regarded as a new burden. Then came the discovery of Eros, and new source of investigation was put before us-a new at a recent meeting of the British Association that Pickering discovered an eighth satellite of Saturn, and the discovery led to the recognition of the possibility of retrograde motion. To explain this, we had to revise our view of the past history of the Solar System. Incidentally, by exciting and stimulating curiosity, it led to the curious pair that circulate about Jupiter, and of the extraordinary quests to be made, no more discoveries to add increasing interest to the science we are met to encourage? The interest to the science we are met to encourage? The
very suggestion of finality is an absurdity. We have mapped out our Solar System with some precision; but what of that great universe of millions of stars in which which a traveler through the wilds of space might pass a hundred times without notice. We have learned much about this universe, though our knowledge of it is stil dim. We see it as a traveler on a mountain-top sees a distant city in a cloud of mist: by a few specks of glimmering light from steeples or roofs. We want to know more about it, its origin and destiny, its limits in tim and space, if it has any, what function it serves in that universal economy. The journey is long, yet we want in knowledge at least, as our motto may remind us, to reach the stars. We cannot do ourselves justice, or ren der any assistance to the scientific aspirations of other if we conceive our duty and our opportunities in any mean and petty spirit. We have to encourage and spur on
others in the race. We also serve who only stand and wait. It may be that we play a worthy part by forming an appreciative audience, by supply that stimulus which is necessary to exertion, by creating that atmosphere in which the tender plant of discovery will grow to perfection. It has been said that there are two parties neces sary for every advance in science: the one that makes it, and the one that believes in it. Possibly to some of us it is given only to believe; but to most of us it is permitted to take a more active share in the progressive march especially if we have the true spirit of the amateur in us. And to impress you with what I mean by the real char acter of the amateur, I cannot do better than quote the definition given by Prof. Hale, who has, I think, spoken so justly of the necessity of cultivating the new ideas
and the new methods that the man unfettered by grooves and shibboleths can introduce. "According to my view," he says, "the amateur is the man who works in astronomy because he cannot help it; because he would rather do such work than anything else in the world, and who, therefore, cares little for hampering traditions or for difficulties of any kind." Prof. Turne says of this definition that it provides both an ambition and a criterion. Surely, in this sense, we all want to be amateurs who find it impossible to stop, who work in astronomy because we cannot help it. Clearly the army of amateurs is the right one for the work; weariness can not touch them; they will go on fighting automatically because they cannot help it. But-oh! those buts!there are dangers to be feared if the zeal of the amateur outruns his discretion. A little knowledge can be a dangerous thing. It is easy to forget past history, to exceeds in value and importance what has gone before. One may be tempted to seek public support and approval from those who do not possess a right judgment in all things. It is easy in these days to create an applauding public - the party whose belief is necessary for the furtherance of science; but to fill this office and fill fairly it must be an informed public. I think the tendency of the age is to treat with undue leniency every strange and unexpected suggestion, because there is a remote chance that it may contain a germ of truth, a pearl of pure water. Let us remember that a new truth will not
suffer ultimately by adverse and even unreasonable criticism, while erroneous theories and false reasoning, supported by the benevolent neutrality of those to whose judgment the scientific world looks for guidance, may be harmful in many ways, especially if they block the way to an independent advance, and encourage hasty and illconsidered generalizations. History is not lacking in examples of this character.

I have spoken to little purpose if you think it is possible for me to suggest the directions in which amateurs may work with advantage. It is originality that is needed not repetition. I may, in conclusion, point out some of the directions in which more information is required, but the manner in which that information is to be garnered is the true province of the amateur. He must find his work for himself. He will only work untiringly and successfully if he has found the work of the right kind. This he must find for himself. No one, I take it, sug gested to Dr. Roberts that the photographing of nebulæ was his metier; to Dr. Anderson that he must watch the stars and discover variables with his naked eye. These and many others whose names will occur to you found their work, and happy is he who gets a new thought from his own brain, and one that will last him a lifetime. But I am anxious that you should know that the harvest is plentiful, that there is more work to be done than workers to do it; so that, in conclusion, I will indicate somed.
directions in which leisure may be profitably employed First of all, let me remind you that there are large depart ments of astronomical inquiry into which star-gazin does not enter. Much active, valuable work is unconnected with an observatory. An institution which has local habitation and a magnificent building command public attention so strongly that earnest work done elsewhere may be overlooked. It cannot be too strongly emphasized that an important part of astronomical work is done away from telescopes and Meridian circles, and requires little more than determination to be successfully followed. I am not speaking now of purely mathematical inquiries. These cannot be followed without years of preparation, which are best surrendered when we are
young. But look at such questions as that of star-drift, which is now vexing the astronomical mind Into this, mathematies scarcely enters. It is a question of comparison and measurement. It is a problem, too, into which new methods can well be introduced by those who are fortunate to have new thoughts, by those who have emancipated themselves, oc who have never been under the influence of the elder Herschel-who inquiry-Airy, Argelander, Struve, and the host of
19th-century prophets. Consider for a moment how the 19th-century prophets. Consider for a moment how the
possibilities of investigation have been enlarged by photography. Hundreds and thousands of stars are recorded on a plate with less difficulty than the positions of a dozen were determined in old times. Certainly the work of a few minutes' exposure of a photographic-plate may take days and weeks for adequate discussion, and remember, further, too, that the directors of many observatories are prepared to place these plates at your service. The comparison of other systems with our own seems a most fructiferous branch of inquiry, offers unlimited capacities. The determination of the absolute dimensions of systems by visual and spectroseopic use of in astronomical research is in a more unsatisfac tory state than stellar parallax, and, hence, knowledge that will enable us to improve its determination will be a most welcome contribution to science. The determination of relative masses in stellar systems follows from a knowledge of distance, and how little we know abou mass, upon the seale on which the stellar cosmos is built. Variable stars offer most attractive subjects for investigation, and do not require large telescopes. This bug bear of large telescopes, suggesting heavy expenditure, is one that must be coped with. I fully agree with what I have read to you from Prof. Hale, that so far as large telescopes prove a deterrent to many an active brain and mind they are a disadvantage. I cannot put it to you too strongly that each instrument has its particular field of work, in which it can accomplish, or permit to be accomplished, various investigations which are not within reach of other kinds of telescopes. We have too long gone upon the principle of endeavoring to get the biggest telescope we can afford, and then finding work we can do with it. That, I believe, is the wrong way to work. We should first consider what we want to do, and then consider what will be the instrumental means required. By way of illustration, I may point out, though the fact is evident to you, that the beautiful photographs of the Milky Way taken by Prof. Barnard could not have been obtained with the 40-inch Yerkes. He employed a 10 inch Brashear lens of 50-inch focus; not a very expensive instrument, but it was suitable for the work for which it was used. That is the point. If we attempted to photo-
graph the Milky Way with the Yerkes telescope, which no one would be mad enough to attempt, we should get a very small region on a very great scale, but one that would fail to give any notion as to the general distribution of stars in the Galaxy. Again, if we turn to the Sun, it will be readily admitted that photography with large instruments is far behind visual observations in smaller, in revealing the minute structure of sunspots. In some respects, the huge refractors of to-day are unsuitable for the observation of solar prominences. Great focal length here is a disadvantage. If you wish to observe the entire prominence, its image in the focal plane of, say, the Yerkes telescope is so large that the slit eannot be opened wide enough to include the prominence without admitting too much light from the sky. For a study of the general characteristics of prominences, the small instrument has a great advantage over the large one. could go on to many other instances, but it would be useess.

The conclusion would be the same-that there is work
for all instruments if the amateur only has the wit to discover it.

One other remark I might make. Some think that situation defeats the end of astronomical investigation, that the bustle and tremor and electric light of a great city do not favor astronomical research, that undisturbed atmosphere and dark skies are the only conditions under which good work can be accomplished. Such excuses may avail the dillettante astronomer; they do not touch the true amateur, who works because he cannot help it. Remember the faintest satellite of Jupiter was discov foggiest metropolis of the world. But I do not look for amateurs to rise from villages and from a stagnant life with the same freedom as from centers of industrial activity. Wealth is necessary to progress in knowledge and the liberal arts. It is only when men are relieved from the necessity of devoting their energies to the immediate wants of life that they can lead intellectual ing commercial centers ing com country as the likeliest ment for the amateur. 